\title{
Tn916 insertion mutagenesis in Escherichia coli and Haemophilus influenzae type b following conjugative transfer
}

\author{
J. Holland, ${ }^{1,2}$ K. J. TowneR ${ }^{1 *}$ and P. Williams ${ }^{2}$ \\ ${ }^{1}$ Department of Microbiology and PHLS Laboratory, University Hospital, Nottingham NG7 2UH, UK \\ ${ }^{2}$ Department of Pharmaceutical Sciences, University of Nottingham, Nottingham NG7 2RD, UK
}

(Received 27 August 1991; revised 14 November 1991; accepted 29 November 1991)

\begin{abstract}
Transposon Tn 916 was shown to be capable of direct conjugative transfer in broth and membrane matings between strains of Escherichia coli K12 and between $E$. coli K12 and Haemophilus influenzae type b. Only Tn916 was transferred, but $\mathrm{Tn} 916$ donor ability was not itself inheritable by the recipients and seemed to be associated with the presence of Tn916 on a non-conjugative pBR322-derived vector in the original donor strain. Transfer of Tn916 by conjugation was found to be an efficient method for producing insertion mutations in the chromosome of recipient cells. Although such insertions were unstable when the cells were grown under non-selective conditions, it was possible to show that over $40 \%$ of the isolated Tn916 insertions in the chromosome of $E$. coli K12 were in gene(s) concerned with histidine biosynthesis, implying that there is a partial hot-spot for Tn916 insertion on the $E$. coli K12 chromosome. When a strain of $H$. influenzae type b was used as a recipient, out of approximately 1500 transconjugants tested, two mutants were isolated with insertions in genes controlling the expression of ironregulated transferrin-binding proteins. These mutants constitutively produced major $76 \mathrm{kDa}$ and minor $90 \mathrm{kDa}$ proteins which bound transferrin, even when grown under iron-sufficient conditions. Tn916 insertion mutagenesis, following transfer by conjugation, is a convenient method for isolating mutations in genes concerned with iron acquisition by this important human pathogen.
\end{abstract}

\section{Introduction}

Tn916 is a $16.4 \mathrm{~kb}$ transposon encoding tetracycline resistance that was originally identified on the chromosome of Enterococcus faecalis strain DS16 (Franke \& Clewell, 1981). It has been demonstrated that $\operatorname{Tn} 916$ is capable of conjugative transfer, in the absence of any detectable plasmid DNA, between Gram-positive genera (Clewell \& Gawron-Burke, 1986), with insertions occurring at different locations on the recipient chromosome (Franke \& Clewell, 1981; Gawron-Burke \& Clewell, 1982). Similar conjugative transposons located on the chromosome have been found in many other Gram-positive genera (Clewell, 1990). All seem to carry a tet $M$ resistance determinant (Burdett et al., 1982) and share strong homology with Tn916 (Clewell \& GawronBurke, 1986).

Previous studies have demonstrated that $\mathrm{Tn} 916$ can be introduced by transformation into Escherichia coli $\mathrm{K} 12$ following in vitro ligation with pGL101, a pBR322derived vector (Gawron-Burke \& Clewell, 1984). The

* Author for correspondence. Tel. (0602) 709163; fax (0602) 422190. recombinant plasmid, designated pAM120, was unstable in $E$. coli $\mathrm{K} 12$ under non-selective conditions, but prolonged growth in the absence of tetracycline was required before Tn916 insertions in the $E$. coli chromosome could be detected (Gawron-Burke \& Clewell, 1984). In contrast, Tn916 introduced into Streptococcus sanguis on a shuttle vector not only excises from the plasmid, but also inserts readily into the chromosome, thereby serving as a convenient insertion mutagen (Gawron-Burke \& Clewell, 1984). Similarly, in Haemophilus influenzae, $H$. parainfluenzae and Neisseria meningitidis, it has been shown that Tn916 will insert at random locations in the recipient chromosome following the introduction of pAM120 by transformation (Kauc \& Goodgal, 1989; Kathariou et al., 1990). The use of pAM120 as a transposon delivery system is particularly efficient because the vector plasmid is unable to replicate in these genera.

Conjugative transfer of $\operatorname{Tn} 916$ was originally demonstrated between Gram-positive bacteria. More recently, conjugative transfer of $\operatorname{Tn} 916$ has also been reported to occur between Gram-positive and Gram-negative bacteria (Bertram et al., 1991). In view of the behaviour of 


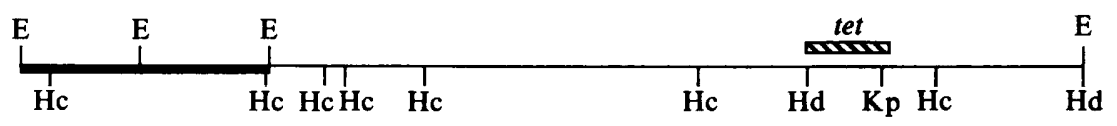

Fig. 1. Restriction map of pAM120 showing the position of the tet $M$ gene. Thick line, pGL101 DNA; thin line, Tn916 DNA; E, EcoRI; Hc, HincII; Hd, HindIII; Kp, KpnI.

Table 1. Characteristics of bacteria and plasmids used in this study

\begin{tabular}{cl}
\hline \hline Bacteria & \\
E. coli K12 & \\
HB101 & $\mathrm{F}^{-}$recA pro lacY ara gal xyl mtl rpsL supE hsdS \\
J53.2 & $\mathrm{F}^{-}$pro met rpoB \\
KT1035 & $\mathrm{F}^{-}$trp lacZ thi rpsL \\
KT1300 & HB101(pAM120) \\
H. influenzae type b & Strain Eagan; invasive clinical isolate \\
JKP1 & Streptomycin-resistant mutant of JKP1 \\
JKP2 & Rifampicin-resistant mutant of JKP1 \\
JKP3 & Tn916 insertion mutant of JKP3 \\
JKP13 & Tn916 insertion mutant of JKP3 \\
JKP14 & \\
Plasmids & Ampr \\
pGL101 & pGL101 : :Tn916 (Ampr , Tetr) \\
pAM120 & \\
\hline \hline
\end{tabular}

Tn916 in certain Gram-negative bacteria following transformation experiments, the primary objective of this work was to assess the potential for Tn916 insertion mutagenesis in Escherichia coli and $H$. influenzae following direct conjugative transfer. In the present paper we: (a) report the conditions required to achieve successful transfer; $(b)$ describe the fate of $\operatorname{Tn} 916$ in the recipient cells; and (c) use $\operatorname{Tn} 916$ to isolate insertion mutants in the genes controlling the expression of transferrin-binding proteins in $H$. influenzae type b.

\section{Methods}

Bacteria and plasmids. The strains of bacteria and plasmids used in this study are listed in Table 1 . Strains of $E$. coli were maintained on airtight nutrient agar slopes at room temperature. Strains of $H$. influenzae type b were maintained at $-70^{\circ} \mathrm{C}$ in Brain Heart Infusion broth (Oxoid) supplemented with NAD (Sigma; $2 \mu \mathrm{g} \mathrm{ml}^{-1}$ ), protoporphyrin IX (PPIX; Sigma; $\left.500 \mathrm{ng} \mathrm{ml}^{-1}\right)$ and glycerol $(20 \%, \mathrm{v} / \mathrm{v})$.

Growth conditions. For experiments in liquid media, strains of $E$. coli were grown with aeration in nutrient broth (NB) at $37^{\circ} \mathrm{C}$. Strains of $H$. influenzae were grown with aeration in Brain Heart Infusion broth supplemented with NAD and PPIX as above (BHINP). For some experiments, growth under iron-restricted conditions was achieved by the addition of the iron-chelator ethylenediamine-di-o-(hydroxyphenylacetic acid) (EDDA; Sigma) to BHINP as described previously (Morton \& Williams, 1989). Nutrient agar (NA) and 'chocolate' blood agar (CBA) were used to subculture $E$. coli and $H$. influenzae strains, respectively. Antibiotics (Sigma) used for selection purposes were incorporated into liquid and solid media at the various concentrations described in Results.

Conjugation experiments. Donor strains containing pAM120 were grown initially on agar plates containing tetracycline $\mathrm{HCl}\left(4 \mu \mathrm{g} \mathrm{ml}^{-1}\right)$, and were then subcultured into $10 \mathrm{ml}$ NB or BHINP, both also containing tetracycline $\mathrm{HCl}\left(4 \mu \mathrm{g} \mathrm{ml}^{-1}\right)$. Following overnight growth at $37^{\circ} \mathrm{C}, 1 \mathrm{ml}$ was inoculated into $10 \mathrm{ml}$ fresh antibiotic-containing broth and incubated with gentle shaking at $37^{\circ} \mathrm{C}$ for $3 \mathrm{~h}$. A culture of the recipient strain was prepared similarly in antibiotic-free broth. For broth matings, donor cultures were centrifuged $(5000 \mathrm{~g}$ for $15 \mathrm{~min}$ ) and the cells resuspended in the same volume of antibiotic-free NB or BHINP immediately before mixing $1: 1$ with the recipient culture. Incubation was under static conditions at $37^{\circ} \mathrm{C}$. Membrane filter matings were as described by Towner \& Vivian (1976), but with overnight incubation of the filter at $37^{\circ} \mathrm{C}$ on the surface of a CBA plate. Selection of $\mathrm{Tn} 916$ transconjugants was on either NA (for $E$. coli) or CBA (for $\boldsymbol{H}$. influenzae), both containing appropriate concentrations of antibiotics (see Results). DNAase I (Sigma; beef pancreas) was dissolved in $0.02 \mathrm{M}^{-\mathrm{MgSO}_{4}}$ and added to certain mating mixtures at a final concentration of $400 \mu \mathrm{g} \mathrm{ml}^{-1}$. All plates were incubated at $37^{\circ} \mathrm{C}$.

Isolation of DNA. Plasmid DNA was isolated as described by Silhavy et al. (1984), and visualized in $0.7 \%$ agarose gels. Total cellular DNA from $H$. influenzae was isolated by a method based on that of Moxon $e t$ al. (1984). Briefly, cells grown overnight at $37^{\circ} \mathrm{C}$ on a shaking incubator in $20 \mathrm{ml}$ BHINP were harvested by centrifugation and resuspended in $3 \mathrm{ml}$ lysis buffer $(0 \cdot 1 \mathrm{M}-\mathrm{NaCl}, 10 \mathrm{~mm}-\mathrm{Tris} / \mathrm{HCl}, \mathrm{pH} 8.0$, $10 \mathrm{~mm}$-EDTA). Aliquots of $500 \mu \mathrm{l}$ were transferred to microfuge tubes and $50 \mu 110 \%(\mathrm{w} / \mathrm{v})$ SDS was added to each tube. The tubes were inverted rapidly three or four times to lyse the cells, and then heated at $60^{\circ} \mathrm{C}$ for $10 \mathrm{~min}$. The tubes were cooled and $27.5 \mu 1$ proteinase $\mathrm{K}$ solution (Sigma; $20 \mathrm{mg} \mathrm{ml}^{-1}$ in $\mathrm{H}_{2} \mathrm{O}$ ) were added to each tube and the contents mixed by inversion. Following incubation at $37^{\circ} \mathrm{C}$ for $1 \mathrm{~h}$, the contents of each tube were extracted twice with $577.5 \mu$ l Tris-buffered phenol (saving the top aqueous layer), followed by one extraction with $577.5 \mu \mathrm{l}$ water-saturated butanol (saving the bottom aqueous layer). The DNA was then precipitated by the addition of twice its volume of absolute ethanol, and stored at $-20^{\circ} \mathrm{C}$ until required.

Preparation of labelled probes. Two DNA probes were used (Fig. 1): (i) the $1.5 \mathrm{~kb}$ HindIII/KpnI fragment of pAM120 which is internal to the tetM gene of Tn916 (Senghas et al., 1988); (ii) the $2.4 \mathrm{~kb}$ EcoRI fragment of pAM120 comprising pGL101 vector DNA and excluding Tn916 (Gawron-Burke \& Clewell, 1984). Probe DNA was prepared, purified and labelled with biotin-14-dATP (Gibco BRL) as described by Carter et al. (1987).

Hybridization experiments. Dot-blots of total cellular DNA extracted from $H$. influenzae were prepared as described by Williams et al. (1990). Cultures of $E$. coli were filtered on to nitrocellulose membranes and treated as described by Carter et al. (1989). Plasmid DNA was transferred from agarose gels to nitrocellulose membranes by electroblotting (Towner et al., 1988). Membranes were air-dried and then baked at $80^{\circ} \mathrm{C}$ for $2 \mathrm{~h}$ to bind DNA to the membrane. Before hybridization, dot-blots were rehydrated and treated with proteinase $\mathrm{K}$ 
as described by Carter et al. (1987). Prehybridization and hybridization with one of the labelled probes was also done as described by Carter $e t$ al. (1987). Detection of a positive hybridization result was by means of a BlueGENE kit (Gibco BRL) using the conditions and protocols recommended by the manufacturer.

Screening of transconjugants for insertion mutations. E. coli $\mathrm{J} 53.2$ transconjugants were first patched on to NA plates containing tetracycline $\left(10 \mu \mathrm{g} \mathrm{ml}^{-1}\right)$ and rifampicin $\left(100 \mu \mathrm{g} \mathrm{ml}^{-1}\right)$, incubated at $37^{\circ} \mathrm{C}$ overnight, and replica-plated on to plates of $E$. coli minimal medium (Vogel \& Bonner, 1956) containing glucose (0.5\%), proline $\left(50 \mu \mathrm{g} \mathrm{ml}^{-1}\right)$ and methionine $\left(50 \mu \mathrm{g} \mathrm{ml}^{-1}\right)$. Auxotrophic mutants unable to grow on the supplemented minimal medium were recovered from the master plates and screened for additional auxotrophic requirements as described by Holliday (1956). Lack of a defined minimal medium meant that it was not possible to screen transconjugants of $\boldsymbol{H}$. influenzae for the acquisition of auxotrophic requirements. However, as part of a parallel study, transconjugants of $\boldsymbol{H}$. influenzae JKP3 were screened for Tn916 insertions in genes controlling expression of outer-membrane transferrin-binding proteins (Morton \& Williams, 1990; Holland et al. 1991). Colony lifts on nitrocellulose membranes (Sambrook et al., 1989) were screened for the ability of transconjugants, grown on the iron-sufficient selection medium, to bind human transferrin in the solid-phase dot enzyme assay employing horse-radish-peroxidase-(HRP)-labelled transferrin, as described by Morton \& Williams (1990). The original selection plates were reincubated at $37^{\circ} \mathrm{C}$ to allow regrowth of colonies. Those colonies which corresponded with a positive transferrin-binding reaction on the nitrocellulose membranes were subcultured on fresh plates of selection medium. Transferrin-binding ability was confirmed by spotting cells resuspended in $10 \mathrm{~mm}$-Tris/ $\mathrm{HCl}$ buffer $(\mathrm{pH} \mathrm{7.4)}$ on to nitrocellulose, and then repeating the dot enzyme assay.

Affinity isolation and electrophoresis of transferrin-binding proteins. Transferrin-binding proteins were isolated from $H$. influenzae essentially as described by Schryvers (1989) and modified by Holland et al. (1991). Briefly, bacterial cell envelopes prepared by sonication of whole cells were first incubated with biotinylated human transferrin. The biotinylated transferrin/transferrin-binding protein complexes were then solubilized from the membrane with $50 \mathrm{~mm}-\mathrm{Tris} / \mathrm{HCl}$ buffer, pH 8.0, containing $100 \mathrm{~mm}-\mathrm{NaCl}, 2 \%(\mathrm{w} / \mathrm{v})$ sodium $\mathrm{N}$-lauroyl sarcosinate (Sarkosyl; Sigma) and $10 \mathrm{~mm}$-EDTA. The complexes were isolated with streptavidine immobilized on agarose beads (Sigma); these were collected, resuspended in SDS-PAGE sample buffer (without 2-mercaptoethanol) and incubated for $30 \mathrm{~min}$ at $37^{\circ} \mathrm{C}$. After centrifugation to remove the beads, samples were applied to $10 \%(w / v)$ SDS-polyacrylamide gels (approximately $2 \mu \mathrm{g}$ protein per lane). Following electrophoresis, proteins were electroblotted on to nitrocellulose and probed with HRP-labelled transferrin as described above for the dot enzyme assay.

Stability of insertion mutations. Mutant strains carrying a Tn916 insertion were grown at $37^{\circ} \mathrm{C}$ overnight in $10 \mathrm{ml}$ of appropriate antibiotic-free broth. Cultures of auxotrophic mutants derived from $E$. coli J53.2 were centrifuged and then resuspended in the original volume of $\frac{1}{4}-$ Ringer's solution. Portions $(0.1 \mathrm{ml})$ of this suspension were spread on to plates of $E$. coli minimal medium containing glucose, proline and methionine to detect revertants to the original J53.2 phenotype. Viable counts were determined by spreading appropriate dilutions on to plates of NA. Appropriate dilutions of $\boldsymbol{H}$. influenzae JKP3 derivatives carrying Tn916 insertions in genes controlling expression of transferrin-binding proteins were spread on to plates of antibiotic-free CBA. Single colonies were patched on to fresh plates of antibiotic-free CBA and then tested for their ability to bind transferrin by spotting cells resuspended in $10 \mathrm{mM}-\mathrm{Tris} / \mathrm{HCl}$ buffer $(\mathrm{pH} 7 \cdot 4)$ on to nitrocellulose and repeating the dot enzyme assay described above.

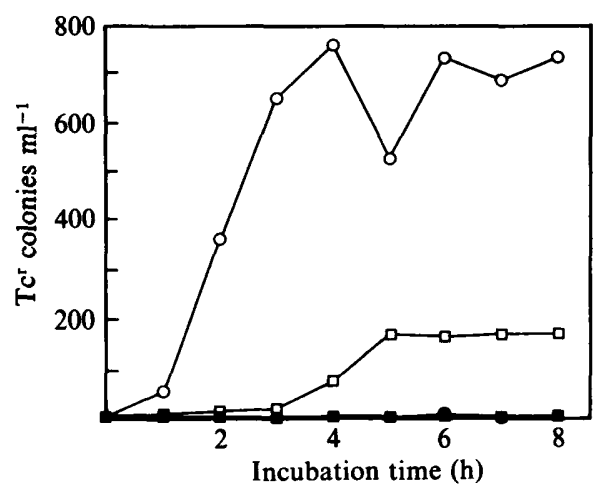

Fig. 2. Example of data obtained with a single donor culture of E. coli $\mathrm{KT} 1300$ in broth conjugation experiments at $37^{\circ} \mathrm{C}$. The same culture of KT1300 was mated with $E$. coli J53.2 (circles) or $H$. influenzae JKP3 (squares) under static (open symbols) or vigorously shaken (filled symbols) conditions.

\section{Results}

\section{Conjugative transfer of pAM120}

Broth and filter mating experiments were performed between $E$. coli strains KT1300 and J53.2, and between KT1300 and $H$. influenzae JKP3. In view of the poor initial expression in $E$. coli and $H$. influenzae of the tet $M$ resistance determinant encoded by $\mathrm{Tn} 916$ (Courvalin \& Carlier, 1987; Kauc \& Goodgal, 1989), it was considered probable that conjugative transfer of $\mathrm{Tn} 916$, if it occurred, would be detectable only with selective tetracycline concentrations marginally above those that would normally be inhibitory for the recipient. Therefore, selection for J53.2 transconjugants was made on NA plates containing rifampicin $\left(100 \mu \mathrm{g} \mathrm{ml}^{-1}\right)$ and tetracycline $\left(10 \mu \mathrm{g} \mathrm{ml}^{-1}\right)$, while selection for JKP3 transconjugants was on CBA plates containing rifampicin $\left(50 \mu \mathrm{g} \mathrm{ml}^{-1}\right)$ and tetracycline $\left(4 \mu \mathrm{g} \mathrm{ml}^{-1}\right)$.

Fig. 2 shows examples of the data obtained in broth matings performed with a single donor culture of $E$. coli $\mathrm{KT} 1300$. Incubation of selective plates at $37^{\circ} \mathrm{C}$ for 48-96 $\mathrm{h}$ was required for transconjugant colonies to develop. The fact that very few transconjugants were obtained when the mating mixtures were shaken vigorously was indicative that transfer of genetic material occurred by conjugation. No significant reduction in the number of transconjugants was observed when mating mixtures contained DNAase I. No colonies were obtained when a cell-free lysate of the donor strain was used instead of intact donor cells.

There was a wide variation in the number of transconjugants generated in broth mating experiments involving different cultures of the donor strain. This observation may simply reflect the varied efficiencies obtainable in broth as opposed to solid surface matings, 
but may also be a consequence of the known instability of pAM120 in E. coli K12 (Gawron-Burke \& Clewell, 1984). Although donor cells were cultured in the presence of tetracycline before mating, the mating mixtures themselves did not contain tetracycline. Control experiments demonstrated that only $3 \%$ of donor cells formed tetracycline-resistant colonies following growth for $6 \mathrm{~h}$ in tetracycline-free broth. The observed variations in the number of transconjugants obtained in broth matings may, therefore, result from rapid and random loss of pAM120 from donor cells before pair formation with recipient cells can occur (see also Discussion). Membrane filter matings generated more reproducible results, with approximately $10^{3}$ transconjugants per plate in matings between strains of $E$. coli $\mathrm{K} 12$, and approximately 50 transconjugants per plate in matings between $E$. coli $\mathrm{K} 12$ and $H$. influenzae JKP3.

\section{Fate of pAM120 in transconjugants}

Tetracycline-resistant transconjugants of $E$. coli J53.2 and $H$. influenzae JKP3 were purified by restreaking on to fresh plates of the initial selection medium. These cultures were then used as donors in mating experiments with $E$. coli KT1035 and $H$. influenzae JKP2. Selection for KT1035 transconjugants was on NA plates containing streptomycin $\left(100 \mu \mathrm{g} \mathrm{ml}^{-1}\right)$ and tetracycline $\left(10 \mu \mathrm{g} \mathrm{ml}^{-1}\right)$, while selection for JKP2 transconjugants was on CBA plates containing streptomycin $\left(100 \mu \mathrm{g} \mathrm{ml}^{-1}\right)$ and tetracycline $\left(4 \mu \mathrm{g} \mathrm{ml}^{-1}\right)$. No colonies were obtained in any of these mating experiments, indicating that the donor ability associated with pAM120 was not itself inherited by the initial transconjugants.

In order to examine further the fate of pAM120 in the initial recipient strains, 153 tetracycline-resistant J53.2 transconjugants and 300 tetracycline-resistant JKP3 transconjugants were patched and regrown on their respective isolation medium and then replica-plated to NA or CBA containing ampicillin $\left(50 \mu \mathrm{g} \mathrm{ml}^{-1}\right)$. All the transconjugants tested were ampicillin-sensitive. This suggested that the pGL101 portion of pAM120, encoding ampicillin resistance, had been lost from the transconjugants. Since the pGL101 portion contains the origin of replication of pAM120, this result also indicated that $\operatorname{Tn} 916$, encoding tetracycline resistance, must have excised from pAM120 and inserted into another replicon in the recipient strain.

\section{Plasmid and DNA probe experiments}

Agarose gel electrophoresis was used to examine 10 J53. 2 and 10 JKP3 tetracycline-resistant transconju- gants for the presence of plasmid DNA. No plasmid DNA was detected in the J53.2 transconjugants, but the original JKP3 recipient strain, together with all 10 transconjugants tested, contained a plasmid of approximately $29 \mathrm{~kb}$. Plasmid DNA from the JKP3 transconjugants was transferred by electroblotting to nitrocellulose membranes and probed with the $1.5 \mathrm{~kb} H$ indIII/KpnI fragment (internal to Tn916) of pAM120. No hybridization was detected, indicating that in each of the J53.2 and JKP3 transconjugants tested, Tn916 had probably inserted into the chromosome.

To examine this point further, dot-blots of total cellular DNA from the J53.2 and JKP3 transconjugants were probed with either the $1.5 \mathrm{~kb} H$ indIII/KpnI fragment of pAM120 (internal to Tn916) or the $2.4 \mathrm{~kb}$ EcoRI fragment of pAM120 (external to Tn916). No hybridization was observed with the $2.4 \mathrm{~kb} E c o R I$ fragment, whereas all transconjugants tested hybridized with the $1.5 \mathrm{~kb}$ HindIII/KpnI fragment. No hybridization of this fragment to total cellular DNA from the original J53.2 culture was detected, but some hybridization was detected with total cellular DNA from the original JKP3 culture (see Discussion).

\section{Isolation and characterization of Tn916 insertion mutants}

E. coli

A total of 153 tetracycline-resistant $E$. coli $\mathrm{J} 53.2$ transconjugants were screened for the acquisition of additional auxotrophic requirements. Of these, 74 failed to grow on initial screening. Further examination revealed that 66 had an additional auxotrophic requirement for histidine, while the other 8 had reverted back to the J53. 2 phenotype. It therefore appeared that Tn916 inserted preferentially into gene(s) concerned with histidine biosynthesis on the chromosome of $E$. coli K 12 .

\section{H. influenzae}

$H$. influenzae type b strain JKP1 binds transferrin only after growth in iron-restricted media (Morton \& Williams, 1990). Tn916 transconjugants were therefore screened for constitutive expression of transferrin binding after growth in iron-sufficient media. Colony lifts of approximately $1500 \mathrm{H}$. influenzae JKP3 transconjugants grown on an iron-sufficient medium were screened for their ability to bind transferrin. Of these, 6 colonies gave an apparent positive result. These colonies were purified by restreaking and were then retested using cells resuspended in Tris/ $\mathrm{HCl}$ buffer. Only two transconjugants (designated JKP13 and JKP14) bound transferrin consistently when grown in iron-sufficient medium (Fig. 3a). 


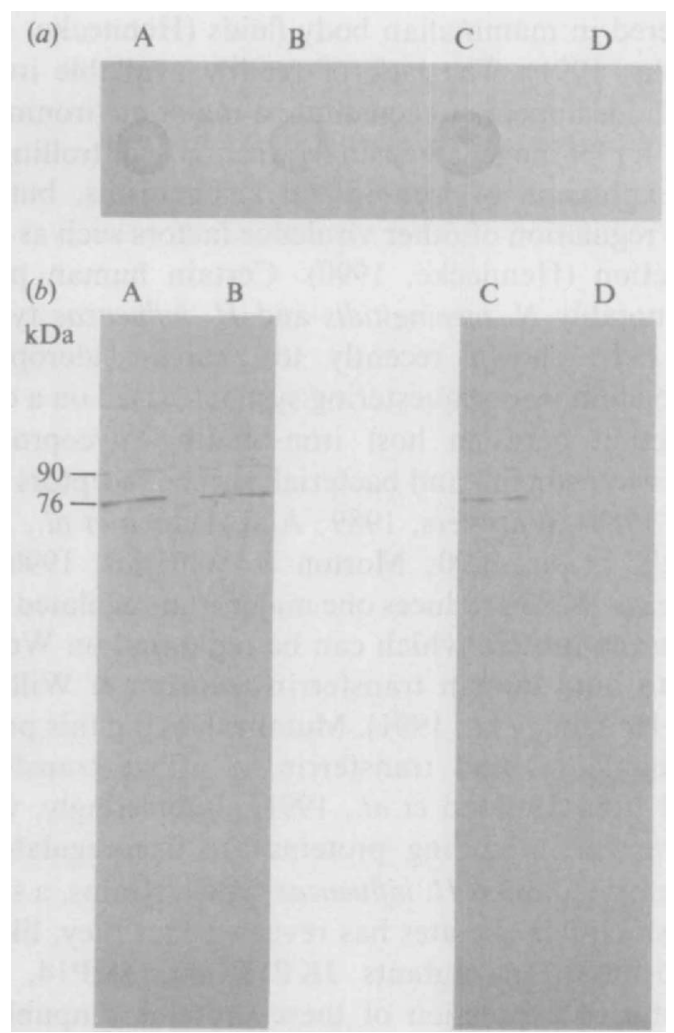

Fig. 3. (a) Dot enzyme assay showing the binding of an HRP-human transferrin conjugate to whole cells of the Tn916 insertion mutants JKP13 (lane A) and JKP14 (lane B), together with the parent strain JKP3 (lanes C and D). Bacteria were grown in iron-sufficient medium (BHINP; lanes A, B and D) or in iron-restricted medium (BHINP + $100 \mu \mathrm{M}$-EDDA ; lane C). (b) Western blot showing binding of an HRP-transferrin conjugate to affinity-isolated transferrinbinding proteins from the Tn916 insertion mutants JKP13 (lane A) and JKP14 (lane B), together with the parent strain JKP3 (lanes C and D). Transferrin-binding proteins were prepared from bacteria grown in iron-sufficient medium (BHINP; lanes $A, B$ and D) or in ironrestricted medium (BHINP + $100 \mu \mathrm{M}$-EDDA; lane C). Molecular masses of transferrin-binding proteins were calculated by comparison with the migration of molecular mass markers in the range $30-200 \mathrm{kDa}$ (Sigma).

Previous work has shown that the interaction between transferrin and $\boldsymbol{H}$. influenzae involves at least one ironregulated outer-membrane transferrin-binding protein (Schryvers, 1989; Morton \& Williams, 1990; Holland et al., 1991). Therefore, the transferrin-binding proteins of JKP13 and JKP14, isolated after growth in ironsufficient medium (Fig. $3 b$, lanes $\mathrm{A}$ and $\mathrm{B}$ ), were compared with those isolated from the parent strain, JKP3, grown under iron-restricted (lane C) and ironsufficient (lane D) conditions. Both mutants constitutively produced major $76 \mathrm{kDa}$ and minor $90 \mathrm{kDa}$ proteins which bound HRP-transferrin (i.e. even when grown under iron-sufficient conditions), while JKP3 expressed these proteins only after growth in media containing the synthetic iron-chelator EDDA. It was concluded that $\mathrm{Tn} 916$ had disrupted a gene(s) concerned with control of expression of the transferrin-binding property.

\section{Stability of insertion mutants}

Ten his derivatives of $E$. coli J53.2, each carrying a Tn916 insertion, were investigated. In no case were revertants to the original $\mathrm{J} 53.2$ phenotype detected (reversion frequency of $<1.8 \times 10^{-9}$ ). In contrast, reversion of the $H$. influenzae mutants JKP13 and JKP14 was detected at high frequency. Of 100 colonies of JKP13 grown on antibiotic-free CBA, only 7 retained the constitutive transferrin-binding phenotype and concomitant tetracycline resistance. The remaining 93 colonies were tetracycline-sensitive, showing that $\operatorname{Tn} 916$ had excised from the chromosome. JKP14 was considerably more stable: of 100 colonies grown on antibioticfree CBA, 98 retained tetracycline resistance and the constitutive transferrin-binding phenotype.

\section{Discussion}

Tn916 is a member of a closely-related family of conjugative transposons which were identified originally in Gram-positive bacteria (Clewell \& Gawron-Burke, 1986). These elements are found normally on the bacterial chromosome, but are able to transpose intracellularly to resident plasmids. It has long been known that $\operatorname{Tn} 916$ is capable of conjugative transfer between numerous Gram-positive genera (Clewell \& GawronBurke, 1986) and, more recently, it has been demonstrated that direct conjugative transfer can occur between Gram-positive and Gram-negative bacteria (Bertram et al., 1991). The present study provides the first evidence that Tn916, when cloned on a pBR322derived vector in $E$. coli $\mathrm{K} 12$, is capable of direct conjugative transfer to other Gram-negative recipient strains. It should, however, be noted that tetracyclineresistant transconjugants were detected only after prolonged incubation on selective media, possibly as a result of poor expression in recipient cells of the tet $M$ resistance determinant encoded by Tn916 (Courvalin \& Carlier, 1987; Kauc \& Goodgal, 1989).

It was of particular interest that the initial $E$. coli $\mathrm{K} 12$ transconjugants received $\operatorname{Tn} 916$ (inserted apparently into the chromosome) but not the vector plasmid, and that the transconjugants carrying a copy of $\mathrm{Tn} 916$ were unable to act as new donors. This is in contrast to the situation observed following the introduction of an intact copy of pAM120 into a new E. coli host by transformation (Gawron-Burke \& Clewell, 1984; this paper). This 
difference might be a copy number effect since pAM120, carrying $\mathrm{Tn} 916$, is a multicopy plasmid with a pBR322derived origin of replication (Gawron-Burke \& Clewell, 1984), and presumably exists in about 20 copies per cell, while only one copy of $\mathrm{Tn} 916$ exists on the chromosome of each transconjugant. This could result in a transfer frequency below the limit of detection. An alternative possibility is that the vector plasmid itself has some role in initiating $\mathrm{Tn} 916$ conjugation in $E$. coli $\mathrm{K} 12$. This could also partly explain the varied mating efficiencies observed with broth cultures. It is known that pAM120 (pGL101 carrying Tn916) is unstable in E. coli $\mathrm{K} 12$ (Gawron-Burke \& Clewell, 1984). If an association between pGL101 and $\operatorname{Tn} 916$ is necessary for $\operatorname{Tn} 916$ conjugation to be initiated in an $E$. coli $\mathrm{K} 12$ donor, the efficiencies of transfer observed would be a reflection of the proportion of donor cells in the mating mixture that carried an intact copy of pAM120.

It has been shown previously that $\mathrm{Tn} 916$ can be used as an insertion mutagen in several Gram-negative genera following its introduction by transformation (Kauc \& Goodgal, 1989; Kathariou et al., 1990). Transfer of Tn 916 by conjugation is an easier and efficient method for producing insertion mutations. When $E$. coli $\mathrm{K} 12$ strain $\mathrm{J} 53.2$ was used as a recipient, it was possible to demonstrate with DNA probes that $\mathrm{Tn} 916$ had inserted into the chromosome. In addition, more than $40 \%$ of the isolated Tn916 insertions were found to be in gene(s) concerned with histidine biosynthesis, implying that there is a partial hot-spot for $\operatorname{Tn} 916$ insertion on the $E$. coli $\mathrm{K} 12$ chromosome. Possible hot-spots for Tn916 insertions have been suggested previously for Clostridium acetobutylicum (Woolley et al., 1989) and $C$. difficile (Mullany et al., 1991). In contrast, Kauc \& Goodgal (1989) have suggested that $\mathrm{Tn} 916$ integrates into many different sites in the $H$. influenzae genome. When $H$. influenzae JKP3 was used as the recipient, it was not possible to demonstrate unequivocally with DNA probes that $\mathrm{Tn} 916$ had inserted into the chromosome. Despite the fact that the original strain of JKP3 was tetracyclinesensitive, some hybridization was detected with the internal tet $M$ fragment from $\operatorname{Tn} 916$ that was used as a probe. The tet $M$ determinant has been shown to occur naturally in a wide range of urogenital and respiratory bacteria, including Haemophilus (Roberts, 1990). It is, therefore, possible that a partial or unexpressed sequence of tetM is already present on the chromosome of JKP3.

One of the original aims of this work was to find a convenient mutagenesis method for $H$. influenzae that involved insertion of a detectable DNA sequence into particular genes of interest. High affinity iron-sequestering systems are known to contribute to bacterial virulence by facilitating the acquisition of this essential bacterial nutrient in the iron-restricted conditions en- countered in mammalian body fluids (Hennecke, 1990; Griffiths, 1991). The lack of readily available iron in body fluids appears to constitute a major environmental signal for pathogens causing infection, controlling not only expression of iron-uptake mechanisms, but also global regulation of other virulence factors such as toxin production (Hennecke, 1990). Certain human pathogens, notably $N$. meningitidis and $H$. influenzae type b, have been shown recently to express siderophoreindependent iron-sequestering systems based on a direct interaction between host iron-binding glycoproteins, such as transferrin, and bacterial surface receptors (Tsai et al., 1988; Schryvers, 1989; Ala'Aladeen et al., 1990; Griffiths et al., 1990; Morton \& Williams, 1990). $H$. influenzae JKP3 produces one major iron-regulated outer membrane protein which can be renatured on Western blots to bind human transferrin (Morton \& Williams, 1990; Holland et al., 1991). Mutants lacking this protein are unable to bind transferrin or utilize transferrinbound iron (Holland et al., 1991). Interestingly, whilst the transferrin-binding proteins are iron-regulated in laboratory-adapted $\boldsymbol{H}$. influenzae type b strains, a survey of fresh clinical isolates has revealed that they, like the Tn916 insertion mutants JKP13 and JKP14, show constitutive expression of these proteins (unpublished observations). The transferrin-binding proteins of such isolates become iron-regulated only after up to 40 in vitro subcultures in iron-rich medium, a finding which suggests that the transferrin iron-uptake system is expressed in vivo during infection.

The Tn916 insertion mutants JKP13 and JKP14, which showed constitutive expression of the outer membrane transferrin-binding proteins, were unstable in non-selective conditions. However, it should be possible to use pulsed-field electrophoresis techniques, in conjunction with cells grown under selective conditions, to locate precisely the positions of these insertion mutations on the $H$. influenzae chromosome (Kauc et al., 1989; Butler \& Moxon, 1990). Conjugation is a simple and effective way of producing such mutations. Their ready availability should enable progress to be made in understanding the regulatory mechanisms involved in this potentially important virulence determinant.

We are indebted to the National Meningitis Trust for their financial support of this project. We thank Dr S. Goodgal for the gift of pAM120.

\section{References}

ala'Aladeen, D., Davies, H. A., Wall, R. A. \& Borriello, S. P. (1990). The $70 \mathrm{kDa}$ iron-regulated protein of Neisseria meningitidis is not the human transferrin receptor. FEMS Microbiology Letters 69, $37-42$. 
Bertram, J., Strätz, M. \& DÜrRe, P. (1991). Natural transfer of conjugative transposon $\mathrm{Tn} 916$ between Gram-positive and Gramnegative bacteria. Journal of Bacteriology 173, 443-448.

BurdeTt, V., INAMINE, J. \& RAJAGOPALAN, S. (1982). Heterogeneity of tetracycline resistance determinants in Streptococcus. Journal of Bacteriology 149, 995-1004.

BUTLER, P. D. \& MoXON, E. R. (1990). A physical map of the genome of Haemophilus influenzae type b. Journal of General Microbiology 136. 2333-2342.

Carter, G. I., Towner, K. J. \& Slack, R. C. B. (1987). Detection of TEM beta-lactamase genes by non-isotopic spot hybridisation. European Journal of Clinical Microbiology 6, 406-409.

Carter, G. I., Towner, K. J., Pearson, N. J. \& Slack, R. C. B. (1989). Use of a non-radioactive hybridisation assay for direct detection of gram-negative bacteria carrying TEM $\beta$-lactamase genes in infected urine. Journal of Medical Microbiology 28, 113-117.

CleWELL, D. B. (1990). Movable genetic elements and antibiotic resistance in Enterococci. European Journal of Clinical Microbiology and Infectious Diseases 9, 90-102.

Clewell, D. B. \& Gawron-Burke, C. (1986). Conjugative transposons and the dissemination of antibiotic resistance in Streptococci. Annual Review of Microbiology 40, 635-659.

Courvalin, P. \& Carlier, C. (1987). Tn1545: a conjugative shuttle transposon. Molecular and General Genetics 206, 259-264.

Franke, A. E. \& Clewell, D. B. (1981). Evidence for chromosomeborne resistance transposon in Streptococcus faecalis capable of 'conjugal' transfer in the absence of conjugative plasmid. Journal of Bacteriology 145, 494-502.

Gawron-Burke, C. \& Clewell, D. B. (1982). A transposon in Streptococcus faecalis with fertility properties. Nature, London 300 , 281-284.

Gawron-Burke, C. \& Clewell, D. B. (1984). Regeneration of insertionally inactivated streptococcal DNA fragments after excision of transposon Tn916 in Escherichia coli: strategy for targeting and cloning of genes from gram-positive bacteria. Journal of Bacteriology 159, 214-221.

GRIFFITHS, E. (1991). Iron and bacterial virulence - a brief overview. Biology of Metals 4, 7-13.

Griffiths, E., Stevenson, P. \& RAy, A. (1990). Antigenic and molecular heterogeneity of the transferrin-binding protein of Neisseria meningitidis. FEMS Microbiology Letters 69, 31-36.

HENNECKE, H. (1990). Regulation of bacterial gene expression by metal-protein complexes. Molecular Microbiology 4, 1621-1628.

Holland, J., TowNER, K. J. \& Williams, P. (1991). Isolation and characterisation of Haemophilus influenzae type $\mathrm{b}$ mutants defective in transferrin-binding and iron assimilation. FEMS Microbiology Letters 77, 283-288.

Holliday, R. (1956). A new method for the identification of biochemical mutants of micro-organisms. Nature, London 178, 987.

Kathariou, S., Stephens, D. S., Spellman, P. \& Morse, S. A. (1990). Transposition of Tn916 to different sites in the chromosome of Neisseria meningitidis: a genetic tool for meningococcal mutagenesis. Molecular Microbiology 4, 729-735.

KaUC, L. \& GoODGAL, S. H. (1989). Introduction of transposon Tn916 DNA into Haemophilus influenzae and Haemophilus parainfluenzae. Journal of Bacteriology 171, 6625-6628.
Kauc, L., Mrtchell, M. \& Goodgal, S. H. (1989). Size and physical map of the chromosome of Haemophilus influenzae. Journal of Bacteriology 171, 2474-2479.

Morton, D. J. \& Williams, P. (1989). Characterization of the outer membrane proteins of Haemophilus parainfluenzae expressed under iron-sufficient and iron-restricted conditions. Journal of General Microbiology 135, 445-451.

Morton, D. J. \& Williams, P. (1990). Siderophore-independent acquisition of transferrin-bound iron by Haemophilus influenzae type b. Journal of General Microbiology 136, 927-933.

MoXon, E. R., Deich, R. A. \& ConNolley, C. (1984). Cloning of chromosomal DNA from Haemophilus influenzae. Journal of Clinical Investigation 75, 298-306.

Mullany, P., Wilks, M. \& TabaQchali, S. (1991). Transfer of Tn916 and $\operatorname{Tn} 916 \Delta E$ into Clostridium difficile: demonstration of a hot-spot for these elements in the $C$. difficile genome. FEMS Microbiology Letters 79, 191-194.

ROBERTS, M. C. (1990). Characterization of the tetM determinants in urogenital and respiratory bacteria. Antimicrobial Agents and Chemotherapy 34, 476-478.

SAMbroOK, J., Fritsch, E. F. \& Maniatis, T. (1989). In Molecular Cloning: a Laboratory Manual, 2nd edn, Vol. 1, p. 96. Cold Spring Harbor, NY: Cold Spring Harbor Laboratory.

SCHRYVERS, A. B. (1989). Identification of the transferrin- and lactoferrin-binding proteins in Haemophilus influenzae. Journal of Medical Microbiology 29, 121-130.

Senghas, E., Jones, J. M., Yamamoto, M., Gawron-Burke, C. \& ClewELl, D. B. (1988). Genetic organization of the bacterial conjugative transposon Tn916. Journal of Bacteriology 170, 245249.

Silhavy, T. J., Berman, M. L. \& Enquist, L. W. (1984). In Experiments with Gene Fusions, pp. 147-148. Cold Spring Harbor, NY: Cold Spring Harbor Laboratory.

TOWNER, K. J. \& VIVIAN, A. (1976). RP4-mediated conjugation in Acinetobacter calcoaceticus. Journal of General Microbiology 93, 355-360.

TOWNER, K. J., Young, H.-K. \& AMYes, S. G. B. (1988). Biotinylated DNA probes for trimethoprim-resistant dihydrofolate reductases types IV and V. Journal of Antimicrobial Chemotherapy 22, 285291.

TSAI, J., Dyer, D. W. \& Sparling, P. F. (1988). Loss of transferrin receptor activity in Neisseria meningitidis correlates with inability to use transferrin as an iron source. Infection and Immunity 56, 3132-3138.

VOGEL, H. J. \& BONNER, D. M. (1956). A convenient growth medium for Escherichia coli and some other micro-organisms. Microbial Genetics Bulletin 13, 43-44.

Williams, P., Morton, D. J., Towner, K. J., Stevenson, P. \& GrIFFITHS, E. (1990). Utilization of enterobactin and other exogenous iron sources by Haemophilus influenzae, $H$. parainfluenzae and $H$. paraphrophilus. Journal of General Microbiology 136, 2343-2350.

Woolley, R. C., Pennock, A., Ashton, R. J., Davies, A. \& Young, M. (1989). Transfer of Tn1545 and Tn916 to Clostridium acetobutylicum. Plasmid 22, 169-174. 